\title{
Erratum to: Chemosensory function assessed with psychophysical testing and event-related potentials in patients with atrophic rhinitis
}

\author{
C. Huart $\cdot$ Ph. Eloy $\cdot$ S. Collet $\cdot$ Ph. Rombaux
}

Published online: 1 September 2011

(C) Springer-Verlag 2011

\section{Erratum to: Eur Arch Otorhinolaryngol}

\section{DOI 10.1007/s00405-011-1670-3}

In addition to their article, the corresponding author wants to submit the following change. He regrets to remove the last sentence "Moreover, the trigeminal responses were absent in all the cases" from the abstract of the online published article, since they recorded trigeminal responses in 3 out of 9 patients.

The online version of the original article can be found under doi:10.1007/s00405-011-1670-3.

C. Huart $(\bowtie) \cdot$ Ph. Rombaux

Unit of Otorhinolaryngology, Cliniques Universitaires

Saint-Luc, Av. Hippocrate 10, 1200 Brussels, Belgium

e-mail: caroline.huart@uclouvain.be

C. Huart · Ph. Rombaux

Institute of Neuroscience,

Université Catholique de Louvain,

Cliniques Universitaires Saint-Luc,

Av. Hippocrate 10, 1200 Brussels, Belgium

$\mathrm{Ph}$. Eloy $\cdot$ S. Collet

Unit of Otorhinolaryngology,

Université Catholique de Louvain,

Cliniques Universitaires Mont Godinne,

Yvoir, Belgium 